\title{
Genetics and Breeding for Drought Tolerance in
}

\section{Food Legumes}

\author{
RajendraDarai, Professor BR Ojha, Dr. A. Sarker, RabendraSah
}

\author{
${ }^{1}$ Senior Scientist and Ph.D. Scholar, Nepal Agricultural Research Council (NARC), Grain Legumes Research Program, Khajura, \\ Nepalgunj, Mid-west Nepal \\ ${ }^{2}$ Assistant Dean, Department of Genetics and Plant Breeding, Faculty of Agriculture, Agriculture and Forestry University (AFU), \\ Rampur, Chitwan, Nepal \\ ${ }^{3}$ Principal Scientist and Coordinator, ICARDA South Asia and China Regional Program, IARI complex, New Delhi, India \\ ${ }^{4}$ Senior Technical Officer, Grain Legumes Research Program, Khajura, Nepalgunj, Mid-west Nepal
}

Tel : +977-9845051523, 9845068141

\begin{abstract}
Food legumes are the wonderful crops and cheapest source of protein in the daily diets of urban and rural masses throughout the world. In these days, its production is almost motionless causing declining per capita availability and high cost of the food legumes made serious threats for food and nutritional security in Nepal. In addition to the inherent low yield potential of many food legumes, there are several diseases, insects and pests and drought. In cowpea drought resistance is reported to be controlled by a single dominant gene. The promising drought tolerant varieties of cowpea were IT98K-1399, IT98K-131-2, IT97K-568-19 and IT98K-452-1. Among the pigeonpea hybrids tested, ICPH 8 and ICPH9 were the most drought tolerant. Likely the line ICPL88039 showed greater drought tolerance. Drought tolerance lentil cultivars were ILL-7979, ILL-10960, ILL -10973, ILL10897, ILL-10821, ILL-10826, and ILL-10835. In fact, drought tolerance on the whole plant basis makes it a complex trait and difficult to manipulate by plant breeders. There is an urgent need for exploration of the plant genetic resources with attributes related to drought resistance in different crop plants. Attention should be concentrated on better understanding of genetic basis of drought resistance through antisense RNA technique. National and International research institutes are being attempted to address the issues by developing extra early varieties combined with resistance to major diseases, insects-pests and tolerant to drought so that some of these legumes may fit in the existing niches in cereal based systems and perform well even in the drought-prone and marginal environments. This paper briefly reviews the challenges, progress and future strategies made in breeding for drought tolerance in major food legumes.
\end{abstract}

Keywords - Food legumes, drought tolerance, genetics, breeding strategy, progress.

\section{INTRODUCTION}

Food legumes such asPhaseolus bean, soybean, chickpea, broadbean, cowpea, blackgram, greengram, lentil, pea, pigeonpea and several other minor legumes are a major source of protein in the daily diets of urban and rural masses throughout the world. However, food legumes production is not keeping pace a per the population growth because of bulk of agriculture solely depend on the green revolution led by wheat-rice cropping system consequently food legumes have been pushed to marginal lands with little care takings. Now the food legumes production is almost stagnant causing declining per capita availability and high cost of the food legumes render in the market. This is really serious issues for food and nutritional security in Nepal. Food legumes data showed increase trends in production over the year 1984, however this amount isn't sufficient for growing population, in fact the production has drastically lacked behind. This has led to the lack of adequate protein and minerals in human diets on one hand and imbalanced soil fertility due to cereal -cereal rotation on the other hand. Food legumes need to increase in production is essential for ensuring balanced human nutrition and sustained soil fertility. In addition to the late maturity and inherent low yield potential of many food legumes, there are several diseases, insects and pests and drought that cause low yields. Drought is especially damaging in legume crops such as bean, cowpea, chickpea, lentils, and pigeonpea which are often grown in drought prone, rainfed and marginal environments. Increasing the production from the limited lands and other constraints is the challenges in the present context. National and International research institutes are attempted to address the issues by developing extra early varieties combined with resistance to major diseases, insects-pests and tolerant to drought so that some of these legumes may fit in the existing niches in cereal 
based systems and perform well even in the drought-prone and marginal environments. This paper briefly reviews the progress made in breeding for drought tolerance in major food legumes.

\section{DROUGHT AND ITS EFFECT ON FOOD} LEGUMES

Agricultural production has directly negative impacts and increase the people's vulnerability due to the natural disasters like floods, droughts, landslides, erratic rainfalls pattern, hailstorms, rising temperature and cold and heat waves. In Nepal, the witness of climate change is the new disease emerging observed in leguminous crops i.e. Stemphylium blight in lentil and Hallo blight in phaseolus bean and more insects incidences i.e. army worm, sucking bugs in soybean, blackgrametc which reduces the crop yields substantially. More than a decade ago preliminary analysis by Mirza and Dixit (1997) found that climate change in the Ganga and Brahmaputra basins is likely to change river flows, which in turn will affect low flows, drought, flood and sedimentation processes. In 1999 Shrestha et al. suggested that temperatures are increasing in Nepal and that rainfall is becoming more variable. Global circulation model (GCM) projections indicate that the temperature over Nepal will increase between $0.5^{\circ} \mathrm{C}$ and $2.0^{\circ} \mathrm{C}$ with a multi-model mean of $1.4^{\circ} \mathrm{C}$, by the $2030 \mathrm{~s}$ and between $3.0^{\circ} \mathrm{C}$ and $6.3^{\circ} \mathrm{C}$, with a multi-model mean of $4.70 \mathrm{C}$, by the 2090s. GCM outputs suggest that extremely hot days (the hottest $5 \%$ of days in the period from 1970 to 1999) are projected to increase by up to $55 \%$ by the 2060 s and up to $70 \%$ by the 2090 s. GCM outputs suggest that extremely hot nights (the hottest $5 \%$ of nights in the period from 1970 to 1999 ) are projected to increase by up to $77 \%$ by the 2060 s and $93 \%$ by the 2090 s. Among the climate vagaries, drought is prevalent in Nepal due to the rainfed farming system. Actually it is the absence of rainfall for long enough time to cause moisture depletion in soil to such a low level that it decreases the water potential in tissues and restricts the expression of full genetic growth and development potential of the plant. Since rainfall is usually erratic in the beginning and towards the end of the rainy season, the rainfed crops are normally subjected to water deficits during seedling and flowering stage and from flowering to seed development stage. However, the crops are grown in arid and semi-arid regions may be affected by intermittent drought throughout the crop growth cycle and suffer more damage. The major food legumes, which are affected by drought, are cowpea, beans, pigeonpea and lentils because of their cultivation under rainfed condition and in low rainfall areas.
Cowpea is widely grown in the semi-arid tropics where drought is a major production constraint and therefore, it suffers considerable damage because of scanty and irregular rains particularly in mid and far western regions of Nepal. Moderate drought during vegetative and reproductive stages reduced bean yield by $20 \%$ and $50 \%$, respectively (Ramirez-Vallejo and Kelly, 1998). Pigeonpea is one of the major pulses in Nepal and its yield is significantly reduced by drought. Global yield losses due to drought have been estimated 2 million tons for pigeonpea. While most of the pigeonpea growing areas are vulnerable to drought, the instances of drought affecting pigeonpea are more common in peninsular India (Chauhan et al, 1992). Lentil is an important cool season food legumes generally grown as a rainfed crop in winter in low rainfall areas $(<400 \mathrm{~mm})$ and on the residual soil moisture after monsoon in West Asia and North Africa. Therefore, it is often subjected to drought. Johansen et al., (1994), reported about 54\% yield loss but prolonged drought spell may result in complete crop failures. Many other pulses are grown in marginal dry areas and they suffer considerable yield losses due to drought.

\section{DROUGHT RESISTANCE -THE MECHANISMS TO COPE WITH DROUGHT}

Drought resistance is defined as the ability of plants to live, grow and yield satisfactorily with limited soil water supply or under periodic water deficiencies (Ashley, 1993, Mitra 2001). Identification of critical stages of crop growth, i.e. the stages at which a crop is more severely affected by drought and the plant response under stress, and more particularly its responses to stress, if any, is important for understanding the mechanism of drought resistance and for evolving appropriate methodology for developing drought resistant varieties. The mechanisms of drought resistance include drought escape, drought avoidance, drought tolerance and drought recovery which are not manually exclusive. Drought escape is defined as the ability of a plant to complete its life cycle before serious soil and water deficits develops and this primarily due to early maturity. Drought avoidance is the ability of plants to maintain relatively high tissue water potential despite a shortage of soil moisture and this occurs from improving water uptake by deep and dense roots, storing water in plant cells and reducing water loss from the plant tissues. Drought tolerance is the ability of plants withstand water deficit with low tissues water potential (Ashley, 1993, Mitra 2001). Drought recovery is the droughts vary in duration, but when rainfall does commence the ability of a genotype (crop variety) to recover quickly and resume active growth 
is an important character. Drought hardening refers to improve of resistance of a genotype to drought as a consequence of a seed/seedling treatment. The various hardening treatments are classified into two groups i) presowing and post sowing treatments. Pre-sowing treatments are applied to seeds before they are planted in the field. A sample seeds treatment consists of soaking the seeds for 24 hours in water and sun drying them, these seeds are sown in the field. Post sowing treatments are applied to young seedlings. A mild moisture stress applied young seedlings is reported to improve their drought resistance during later stages of growth. Thus, the overall crop performance under moisture -stress depends upon the combination of these mechanisms. Drought resistance appears as a complex trait because several factors the mechanisms (in shoot and roots) operate to enable plants to cope with the drought stress. This includes

i) Morphological traits such as earliness, reduced leaf area, leaf rolling, wax contents, efficient rooting system, pubescence of aerial organs, reflectance of incoming solar radiation, increased heat dissipation through decreased boundary layer resistance at the organ level(narrow leaves, awns), stability in yield and reduced tillering.

ii) Physiological traits such as reduced transpiration, high water use efficiency, stomatal closure and osmotic adjustments and

iii) Biochemical traits such as accumulation of proline, polyamine, trehalose etc., increased nitrate reductase activity and increased storage of carbohydrates.

Stomatalconductase, leaf photosynthetic rate ,carbon isotope discrimination ratio,canopy temperature ,leaf area potential, water use efficiency, biomass and harvest index , and seed yield in drought - stressed (DS) and non-stressed (NS) conditions have been used for screening for drought tolerance (White and Singh, 1991).However, dry weight especially seed yield under drought - stressed (DS) and non-stressed (NS) conditions, reduction in seed yield due to drought stress and drought susceptibility index are most reliable integrated measures of cultivar response to drought - Also, these traits have commonly been used as selection criteria (Abebe and Brick, 2003; Teran and Singh, 2002).

\section{SOURCES OF DROUGHT RESISTANCE}

There are three main sources of drought resistance in crop plants: 1) Cultivated species, 2) Germplasm collections/landraces, and 3) Wild relatives and wild species. Transfer of drought resistance is easy from cultivated variety and germplasm of cultivated species, because such material can be easily used in the breeding programmes. Moreover, there is no problem of cross incompatibility. When the source of drought resistance is a wild species, the transfer of resistance poses several problems such as cross incompatibility, hybrid in-viability, hybrid sterility and linkage of several undesirable genes with desirable ones. Wild sources of drought resistance have been reported in wheat, sugarcane, tomato, and several other crops. For example wheat wild species Aegliopskotsehyi, Ae.variabills, Ae.speltoider, Ae.Umbellulata, Ae.squarrosa is the resistant for drought likely sugarcane wild species Saccharumspontaneum is the resistant for drought and salinity.

\section{INHERITANCE OF DROUGHT RESISTANCE}

The identification of genes responsible for morphological and physiological traits and their location on chromosome have not been possible, but their inheritance pattern and nature of gene action have been reported. Polygenic inheritance of root characters is reported by Ekanayake et al. The long root and high root numbers are controlled by dominant alleles and thick root tip by recessive alleles. However, leaf rolling and osmotic adjustment have shown monogenic inheritance. Tomar and Prasad reported a drought resistance gene, Drt1 in rice, which is linked with genes for plant height, pigmentation, hull color and awn, and has pleiotropic effect on the root system. Similarly, in cowpea drought resistance is reported to be controlled by a single dominant gene. Though some more reports in this regard for other traits are available, further investigation is the need of the hour to have better understanding of genetic control of morphological and physiological traits contributing to drought resistance.

\section{GENETICS OF PLANT TRAITS ASSOCIATED WITH DROUGHT RESISTANCE}

Genetic variation has been observed for a number of adaptive traits related to environmental stress. These include physiological traits, such as maintenance of relatively higher leaf-water potential under soil water deficits, osmotic adjustment, tolerance to stress in plant or organ growth rate, plant recovery on rehydration, tolerance to stress in plant or organ growth rate, plant components, tolerance in enzyme activities, tolerance in translocation, stability of cellular membranes; chemical traits such as proline accumulation; epicuticular wax content; and morphological traits, such as root growth, leaf size, leaf area per plant, leaf orientation, tiller survival and organ pubescence. 
Until such time as routine screening techniques are developed and the relationship between these adaptive traits and crop performance under stress is clearly established, incorporation of adaptive traits from one genotype to another shall remain elusive from the viewpoint of practical plant breeding. Genetic studies indicate moderate to high heritability so all three traits may be susceptible to breeding and selection pressure. Epidermal conductance is the most stable, and can be measured on well-watered plants. However, measurement of osmotic adjustment and lethal RWC requires that the plants be stressed. Moreover, the expression of both traits is affected by the severity of the drought. Physiological studies have shown that soybean genotypes combining strong expression of all three traits recover more effectively after the relief of very severe water stress. However, these traits are time-consuming to measure and difficult to handle in a breeding program. Current research is therefore exploring whether molecular markers can be developed to help select prospective genotypes. Selection for drought resistance will therefore continue to be primarily based on yield assessment under stress conditions as concluded by Asana (1957).

\section{PROCEDURE FOR BREEDING DROUGHT RESISTANT VARIETIES}

The usual breeding strategies are adopted for developing drought-resistant varieties

1. Selection of drought escaping varieties: Selection of early maturing varieties that are likely to escape drought is the first line of defense against drought and the most widely used approach.

2. Selection of genotypes under defined drought conditions: This involves selection of varieties under specified drought environments and applying appropriate selection pressure.

3. Incorporation of relevant drought resistance factors (traits) into agronomical superior varieties under optimum conditions to make them suitable for suboptimal conditions. Usual breeding methods are used for incorporating relevant genes. For example

\section{Combining selection for drought resistance traits and high yield potential}

Parents:

A

Traits

Year 5

Year 6

www.ijeab.com
(DR)

$\mathrm{X}$

B

F1

F2

F3

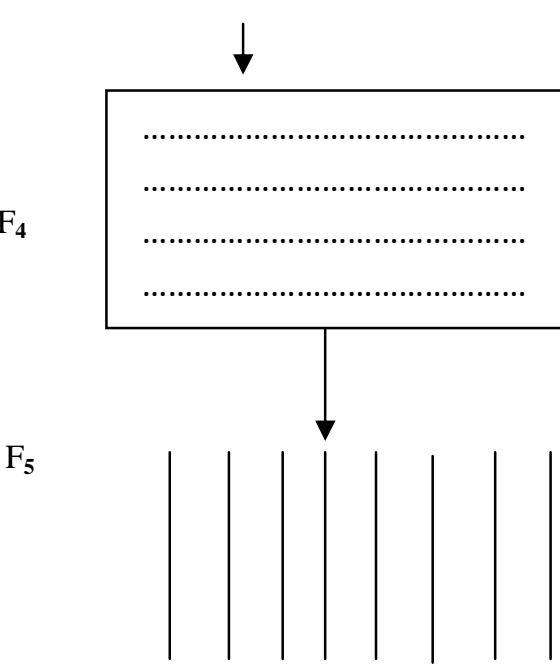

Superior plants selected

Grow under optimum moisture level

Individual plant progenies grown

Superior progenies selected and harvested separately 
(Moisture stress)

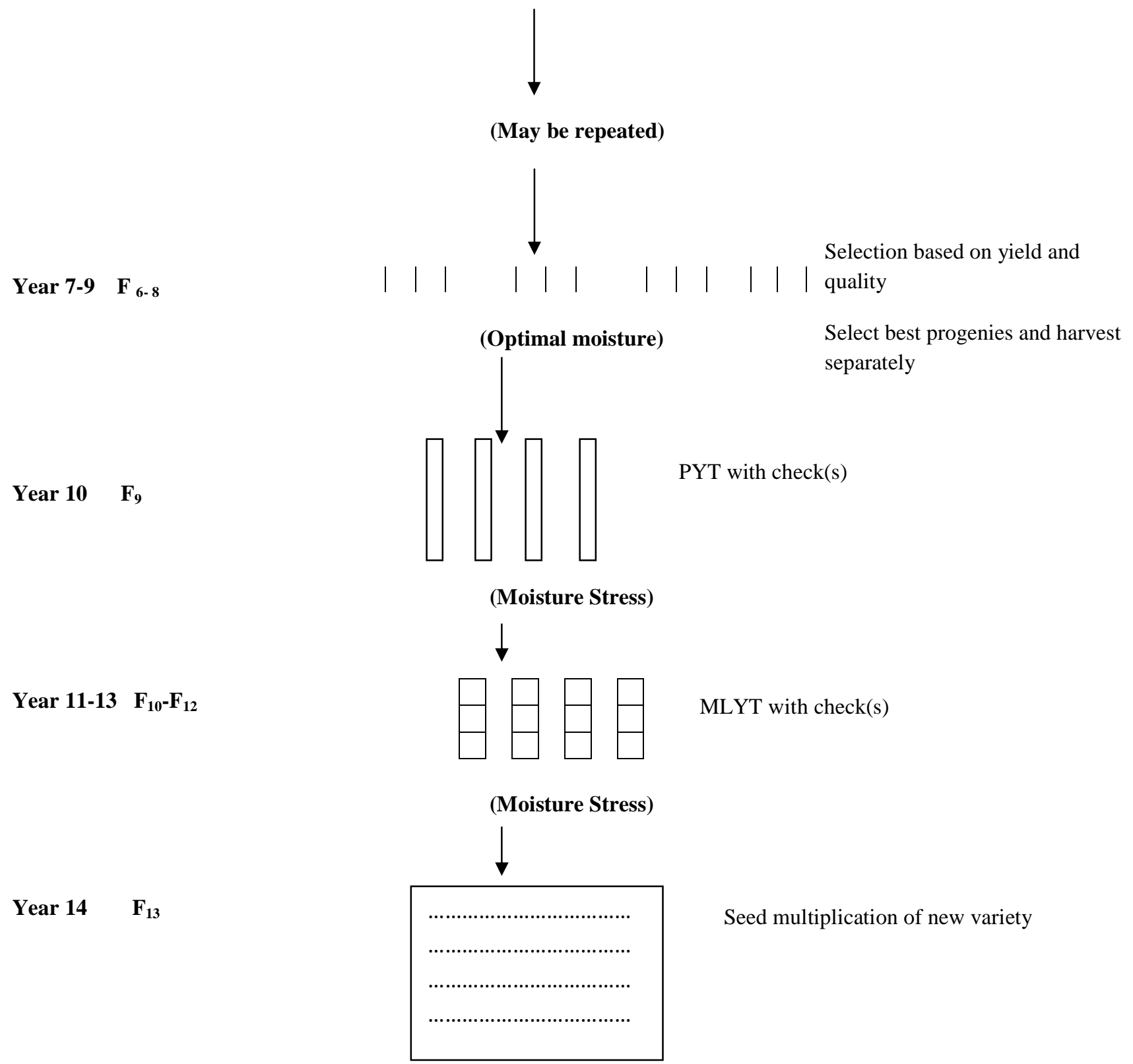

Seed Multiplication

Fig. A breeding approach for drought resistance based on a combined use of optimum and moisture stress environments

\section{SCREENING METHODS FOR DROUGHT RESISTANCE}

Several methods have been used to estimate drought resistance and water use efficiency that involve measurement of water potential, relative turgidity and diffusion pressure deficit, chlorophyll stability index, biochemical indicators and carbon isotope discrimination
etc(Bates et al., 1973, Turk and Hall, 1980, Morgan,1984, Yadava and Patil 1984, Hall et al., 1990, Hall et al., 1997, Mitra,2001). However, most of these methods are expensive and time consuming and therefore, are not very efficient for screening a large number of plants in segregating populations. Screening under field conditions is not always possible because of unpredictability and variable intensity 
of drought stress and using rain-shelters are expensive and not practical for screening a large number of breeding lines. Also, screening for drought tolerance in the field off season using controlled watering is often not relevant to the environment of the real growing season particularly when temperature and photosensitivity play important role in crop growth and productivity. Also most of the studies in the past have dealt with screening for drought resistance as a whole and not individual components involved in drought tolerance ( Watanabe et al., 1997). This might cause variable results depending upon which factors were operational during the screening. However, if these factors and mechanisms can be separated and investigated individually, the components leading to drought tolerance will appear less complex and may be easy to manipulate by the breeders. For example, breeding for early maturity, photosensitivity, indeterminacy, epicuticular wax, pubescence and awns which indirectly affect the ability of plants to cope with drought is easy because these traits are simple inherited and can be easily screened and incorporated in improved varieties. For other traits such as osmotic adjustment and stomatal regulations, which indirectly control the drought tolerance of the plants, the deal approach would be to study the shoot drought tolerance and root characteristics separately and identify genes(s) responsible for stomatal behavior, osmotic adjustment, root architecture and combine them in improved varieties.

A simple wooden box screening method for shoot drought tolerance in cowpea was developed which eliminates the effects of roots and permits non-destructive visual identification of shoot dehydration tolerance. Also, 'a root box pin -board' method has also been developed to study two dimensional root architecture of individual plants(Singh and Matsui, 2002).Using these methods, two mechanisms of shoot drought tolerance in cowpea have been identified and major differences for root architecture among cowpea varieties. The box method is simple and non-destructive for drought tolerant plants and offers flexibility in terms of size of operation as boxes can be larger or smaller depending upon the need. The test materials can be homozygous lines or segregating populations and the drought tolerant plants can be saved and transplanted for further progeny testing and selection. Combining deep and dense root system with shoot dehydration tolerance results into highly drought tolerant plants and drought tolerant plants or progenies in cowpea at seedling stage that showed good correlation with drought tolerance $t$ vegetative and reproductive stages.

\section{SCREENING FOR ROOT CHARACTERISTICS}

Screening for root characteristics is difficult because of the underground distribution of roots and associated soil variations. Several methods have been used to estimate root length, density, volume and distribution in the field (Krishnamurthy et al., 1996). The 'augar method' provides for a three dimensional volumetric measure of soil-root relationship. However, this has large sampling variations. The 'monolith method' in which soil samples of an area of $20 \mathrm{x} 30 \mathrm{~cm}$ to a depth of 10 or $15 \mathrm{~cm}$ are successively recovered and the roots are washed in a $1 \mathrm{~mm}$ sieve. The method is less variable because of large sample size. However, these methods are suitable only for limited comparisons. The rhizobium or minirhizobium methods are more efficient and permit non-destructive continuous study of root systems but these involve expensive set up and equipment and not practical for screening large number of segregating populations. Also, the root density estimates using minirhizotron method do not compare well with augar or monolith method (Krishnamurthy et al., 1996). Recently a 'root - box pin' method has been developed which permits two dimensional study of root systems of a large number of plants or progenies with limited resources and great simplicity(Singh and Matsu,2002).Using this method, (Singh and Matsu,2002) observed two types of root systems in cowpea

i) Umbrella type in which most of the roots are horizontally spread in the top 9" of the soil with only tap root going down and

ii) Deep and dense type in which roots have spread in horizontal as well as deep down the soil.

Thus, if the rains stop, the umbrella type shows sign of wilting within a week whereas the deep and dense type doesn't show wilting until two weeks. Thus, combining the shoot dehydration tolerance and deep and dense system would confer extra tolerance to drought.

\section{PROGRESS IN BREEDING FOR DROUGHT TOLERANCE}

Conventional breeding requires the identification of genetic variability to drought among crop varieties, or among sexually compatible species, and introducing this tolerance into lines with suitable agronomic characteristics. Although conventional breeding for drought tolerance has and continues to have some success, it is a slow process that is limited by the availability of suitable genes for breeding. Some examples of conventional breeding programs for drought tolerance are the development of rice, wheat and Indian mustard varieties tolerant to salt and to alkali soils by the Central Soil Salinity Research Institute in Karnal, India; 
the development of maize hybrids with increased drought tolerance; efforts to incorporate salt tolerance to wheat from wild related species; and the incorporation of drought tolerance as a selection trait in the generation of new maize and wheat germplasm by the International Maize and Wheat Improvement Center.

The development of tolerant crops by genetic engineering, on the other hand, requires the identification of key genetic determinants underlying stress tolerance in plants, and introducing these genes into crops. Drought triggers a wide array of physiological responses in plants, and affects the activity of a large number of genes: gene expression experiments have identified several hundred genes which are either induced or repressed during drought. Major differences among and within crop species have been reported and different strategies to breed drought resistant varieties have been suggested (Blum, 1985, Arraudeau, 1989, Acevedo and Ceccarelli, 1989, Walker and Miller, 1986, Ashley, 1993, Boyer, 1996, Mitra, 2001). However, success in breeding for drought tolerance has not been as pronounced in the past as for other traits in any crop. This is partly due to lack of simple, cheap and reliable screening methods to identify drought tolerant parents and select drought tolerant plants and progenies from segregating populations and partly due to complexity of factors involved in drought tolerance. However, the recently developed improved methods of screening have led to good progress in breeding for drought resistance in cowpea and other crops ( Malhotra et al., 2004).

\section{Cowpea}

Using the box screening for shoot drought tolerance and 'root -box pin-board' screening for root architecture, it has been possible to identify cowpea varieties with enhanced level of shoot drought tolerance and varieties with well distributed deep root system. These have been crossed to combine the two characteristics and a number of new improved breeding lines with high level of drought tolerance have been developed. Also, a number of selected local lines and improved breeding lines have been screened using box screening and a number of drought tolerant lines have been identified and tested in drought prone areas. Some of the selected drought tolerant and susceptible varieties were evaluated in the field at Minjibir(Nigeria) and Zinder(Niger Republic) at normal date of planting (nonstressed) and late planting towards the end of the rainy season(stressed). The most promising drought tolerant varieties were IT98K-1399, IT98K-131-2, IT97K-568-19 and IT98K-452-1 and these were much superior in performance than the known susceptible checks such as IT95K-238-3 and TVU778. These results indicate that box method can be used to screen for drought tolerance of new breeding lines to reduce their numbers before field testing. A large number of segregating populations involving shoot drought tolerance and deep root system have been developed and these are at different stage of evaluation.

\section{Pigeonpea}

Even though no directed effort for breeding for drought tolerance in pigeonpea has been made, improvement in adaptation to drought in ICRISAT's pigeonpea breeding program have been simply achieved by improving some yield contributing traits. Pigoenpea breeding program elsewhere have very successfully developed genotypes that escape or avoid drought. First they have been able to develop cultivars of short duration types of 90 to 150 days to maturity which has made it possible tomatch flowering time with periods of soil moisture availability (Chauhanetal., 1999). Such genotypes have given similar or higher yield while taking less time to mature than traditional cultivars (Saxena and Yadav ,1975, Chauhan et al., 1987). Among the pigeonpea hybrids tested, ICPH 8 and ICPH9 were the most drought -tolerant .However, there was no indication of superiority of indeterminate type over determinate types or vice versa. Screening under rainout shelters the line ICPL88039 showed greater drought tolerance in (Chauhan et al., 2002). The drought screening under rainout shelter through reliable has limitations of space and that pigeonpea can't be grown year after year at the same place. Development of relatively synchronously flowering and podding ICPL 88039 has enabled increase in pod set under drought and escape insect attack. ICPL88039 has become popular in Indo-Gangetic plain zone in rotation with wheat. This extra early variety can be cultivated in the elevation of 500-2000m. ICPL88039 is popular in mid and far western hills of Nepal particularly in the Surkhet, Dailekh and Bajura districts.

\section{Lentil}

This is an important cool season food legume generally grown as a rainfed crop, lentil is grown in about 4 million ha with annual production of about $3.8 \mathrm{~m}$ tons (FAO,2004). In South Asia lentil is grown in residual soil moisture after monsoon and it is reported that can be grown in winter in $<400 \mathrm{~mm}$ rainfall condition, therefore subjected to drought .Johansen et al.(1994),reported about 54\% yield loss but prolonged drought spell may result in complete crop failure. Drought escape is preferred strategy in lentil to minimize the impact of drought stress. Early flowering and maturity with high yield potential are the major components of drought escape in lentil (Silim et al., 1993).Therefore; screening of lentil genotypes with early seedling vigor, faster growth, early flowering and maturity with high 
biomass development is being carried out at ICARDA and some of the recently identified genotypes with higher level of drought escape traits are : ILL6024, ILL7504, ILL7618, ILL7981, ILL8095, ILL8138, ILL8621, ILL9830, ILL9844, ILL9850, ILL9920, ILL9921, ILL9922and ILL9923(Malhotra et al., 2004).

The recently developed box screening method (Singh et al., 1999a) was used to screen for dehydration tolerance. Based on days taken to wilting, the following lines are scored as dehydration tolerant: ILL759, ILL6465, ILL6467, ILL7005, ILL7940, ILL7955, ILL7972, ILL8072, ILL7980, ILL8075, and ILL8090 (Malhotra et al., 2004). Hamdi and Erskine (1996) found that wild Lens species have high level of drought tolerance. Sarker et al., (2005) observed that stem length, tap root length and lateral root number are key traits for drought tolerance in lentil. These traits were highly heritable and correlated among them, and with yield. Among a total of forty genotypes, ILL6002 exhibited significantly superior root and shoot traits and yield. Several drought tolerant cultivars have been released by various national programs (Sarker et al., 2001). A recently released drought tolerant cultivar, Idlib-3 in Syria produced 0.825 t/ha under $195 \mathrm{~mm}$ rainfall compared to susceptible lines, which produced $<500 \mathrm{~kg} / \mathrm{ha}$ in that particular year. Drought tolerance and well adapted lentil cultivars ILL-7979, ILL10960, ILL-10973, ILL-10897, ILL-10821, ILL-10826, and ILL-10835 were selected from Rampur (Darai et al., 2014). The germplasm received from ICARDA.

Rice

Among the drought tolerant genotypes, in AYT 100-120C the genotypes IR79899-B-179-2-3 IR81431-B-B-141, IR79913-B-362-B-3， IR79907-B-425-B-4， IR83928-B-B, IR80461-B-7-1 and IR78908-193-B-3-B were found superior. In AYTGT120C, IR70210-39-CPA-7-1-1-4-2, IR81896-B-B-74-B , IR81896-B-B-68-B, IR78875-207-B3-B， IR79615-9-3-1-3, IR05N455, IR80408-B-43-3, RAM520C IR 81896-B-B-362, IR 81896-B-B-408, IR 81896-B-B-158, IR 81896-B-B-348, IR 81896-B-B-10 and IR 81896-B-B-394 were found superior. In ADAYSEL IR 64C, IR 77298-5-6-25, IR 77298-12-7-13, IR 77298-5-6-11, IR 77298-12-7-17and IR 77298-12-7-25 were found superior. In DONER C IR57514-PMI-5-B-1-2, IR77080-B34-1-1, Radha 4, Apo, IR77298-14-1-2-10, IR77080-B-341-1 were found superior. Similarly in OYTC IR83377-B-B93-3, IR83383-B-B-129-1, IR8388-B-B-8-3 and IR83376B-B-150-4 were found superior (Annrep, 2011). NARC/NRRP has been released six rice drought tolerant varieties Sukha Dhan-1, Sukha Dhan-2, Sukha Dhan-3, Sukha Dhan-4, Sukha Dhan-5, Sukha Dhan-6 for general cultivation of different agro-domains of Nepal. Among which SukhaDhan -3 is popular in mid and far western terai.

\section{FUTURE CHALLENGES TO THE AGRICULTURIST}

The importance and urgency of developing high yielding drought resistant cultivars that use water efficiently and stabilize yields in drought-prone environments can never be over emphasized. The traditional approach of studying drought tolerance on the whole plant basis makes it appear as a complex trait and therefore, difficult to manipulate by plant breeders. However, the new specific screening methods for shoot dehydration tolerance and root architecture have provided a simplified approach to the study of drought tolerance in cowpea and may lead greater progress in breeding for drought tolerance in crops and therefore, a combination of conventional and biotechnological approaches is needed to make rapid progress in breeding for drought tolerance.

Drought stress induces various biochemical and physiological responses in plants. Metabolic pathways involving the synthesis of different metabolites such as polyamine, carbohydrate, proline and trehalose etc. have shown to be associated with drought resistance. Recently, a number of genes have been described in arabidopsis, cowpea and rice etc. that respond to drought at the transcriptional level. Studies are underway to analyze the functions of stress inducible genes not only to understand the molecular mechanisms of stress tolerance and the responses of higher plants but also to improve the stress tolerance of crops by gene manipulation (Motoaki Seki et al., 2001). A number of studies are also underway to identify markers associated with drought tolerance in cowpea, bean and other crops to initiate marker assisted selection to develop drought resistant genotypes more effectively as their expressions are independent of environment effects (Schneider etal., 1997). There is a need to allocate additional resources and multidisciplinary teams to address the challenging tasks of breeding for drought tolerance especially in grain legumes which are not only grown in marginal environments but they also receive less research funds.

\section{FUTURE STRATEGIES}

The future research programmes for drought resistance should consider the following strategies:

1. There is an urgent need for exploration of the plant genetic resources with attributes related to drought resistance in different crop plants and their characterization to facilitate transfer of desired traits 
through conventional plant breeding or biotechnological method.

2. A single trait cannot confer drought resistance satisfactorily. Therefore, breeding programme for drought resistance should aim at pyramiding a number of relevant traits in a crop.

3. Plant genetic engineering also generated transgenic plants with only one transgene in all cases. Many different genes responsible for biosynthesis of different solutes and osmolytes conferring drought resistance should be considered for transfer in a crop plant at a time.

4. Attention should be concentrated on better understanding of genetic basis of drought resistance through antisense RNA technique, observing the effect of expression level of different enzymes/ proteins in different biochemical pathways on drought resistance.

5. Several stress proteins (such as LEA, dehydrin, etc.) are synthesized and accumulated in plant tissues under drought condition. A comparative assessment of various polypeptides produced in response to drought, between sensitive and tolerant genotypes may be used in identification of protein marker, which could help in producing transgenic drought resistant plants.

6. A multidisciplinary approach involving genetics, biochemistry, biotechnology, physiology, plant breeding and crop science will be appropriate to assess the complicated and integrated response of plants to drought and to evolve superior drought-resistant genotypes.

7. Crop modeling simulation predicts the future climate scenario and helps farmers to alert and using adaptation technologies.

\section{ACKNOWLEDGEMENTS}

The authors would like to express sincere thanks to National Coordinator of Grain legumes Research Program for facilitating the review materials and ICARDA, AVRDC, IITA for supporting genetic materials in the breeding studies. The research team of GLRP breeding units is gratefully acknowledged. We also would like to thanks to the Department of Genetics and Plant breeding, AFU, Rampur for selecting the article topics and editing the paper. All personalities who directly and indirectly provided valuable feedbacks and suggestions on this paper are also appreciated. Lastly, but not least special thanks goes to the editors of International Journal of Environmental, Agricultural and Biotechnology (IJEAB) for selecting the paper and appropriate suggestion.

\section{REFERENCES}

[1] Abebe, A. and M.A. Brick, 2003.Traits associated with dry edible bean productivity under diverse soil moisture environments. Euphytica, 133: 339-347

[2] Acevedo, E. and S. Ceccarelli, 1989. Role of physiologist -breeder in breeding program for drought resistance conditions .P. 117-139. In W.G. Baker (ed) Drought Resistance in cereals $\mathrm{CAB}$ Intl. Wallingford,London.

[3] Armento-Soto, J. L., Chang, T. T., Loresto, G. C., and O'Toole, J. C., J. Soc. Adv. Breed. Asia Oceania, 1983, 15, 103-116.

[4] Arraudeau, M.A. 1989. Breeding strategies for drought resistance. P. 107-116. W.G. Baker (ed) Drought Resistance in cereals CAB Intl. Wallingford,London.

[5] Asana, R.D.1957. The problem of assessment of drought resistance in crop plants Ind.J. Genet. \& Pl. Breed., 18, 370-378

[6] Ashley, Jhon 1993. Drought and crop adaptation . p. 46-67. In J.R.J. Rowland(ed). Dryland farming in Africa 1993. Macmillan press Ltd, London.

[7] Baenziger, P. S., Wesenberg, D. M. and Sicher, R. C., Crop Sci., 1983, 23, 116-120

[8] Bates, L. S., R.P. Waldren and I.O. Teare. 1973. Rapid determination of free proline in water stress studies. Plant and Soil,38:205.

[9] Blum, A.1985.Breeding crop varieties for stress environments.CRC critical Reviews in Plant Sciences, 2:199-238.

[10] Boyer, John S. 1996. Advances in drought tolerance in plants; Advances in Agronomy, 56:189-218

[11] Chauhan, Y.S. ,Vanketaraman,N. andSheldrake,A.R. 1987. A perennial cropping system from pigeonpea grown in drought research; Food Legume Newsletter,25;9.

[12] Chauhan, Y.S., Saxena,K.B., and Subbarao,G.V., 2002 Experiences in field screening for drought tolerance in pigeonpea .p. 138-146.

[13] Chauhan, YS, Saxena,NP, Rao, RCN, Johansen,C.andRavindranath, K. 1999 .Portable rainout shelter, a useful tool in drought research .Food legume Newsletter, 25:9

[14] Ekanayake, I. J., O'Toole, J. C., Garrity, D. P. and Masajo, T. M., Crop Sci., 1985, 25, 927-933.

[15] Hall, A.E., S. Thiaw, A. Ismail and JD Ehlers, 1997. Water Use efficiency and drought adaptation of cowpea .p.141-146

[16]Hamdi, A and Erskine, W.1996. Reaction of wild species of the genus Lens to drought, Euphytica,91:173-179 
[17] Krishnamurthy, LC, C. Johansen and O.Ito.1996. Genotypic variation in root system development and its implication for drought resistance in chickpea .p 235-250.

[18]Lakshminarayana, R., Patel, G. L. and Jaisani, B. G., Indian J. Genet., 1979, 39, 485-491.

[19] Mai Kodomi, Y., Singh, B. B., Terao, T., Myess Jr., O., Yopp, J. H. and Gibson, P. J., Indian J. Genet., 1999, 59, 317-323.

[20] Malhotra,R.S., Sarker, A. and Saxena,MC. 2004.Drought tolerance in chickpea and lentil present status and future strategies.p. 257-273

[21] Mitra, J. 2001. Genetics and genetic improvement of drought tolerance in crop plants. Current Sci.,80: 758763

[22] Morgan, J. M., Aust. J. Plant Physiol., 1991, 18, 249257. 20. Tomar, J. B. and Prasad, S. C., Indian J. Agric. Sci., 1996, 66, 459-465.

[23] Morgan,JM.1984.Osmoregulation and water stress in higher plants .Ann.Rev.Plant Physiol.35:299-319.

[24] Ojha, BR.2015. Principle of Plant breeding I(PLB 601)

[25] Ramirez-Vallejo, P. and J.D.Kelly, 1998.Traits related to drought resistance in common bean.Euphytica,99:127-136

[26] Sarker, A., Eriskin,W. and Singh,M. 2005.Variation in shoot and root characteristics and their association with drought tolerance in lentil landraces . Genetic resources and Crop Evolution, 52:87-95

[27] Sarker, A., Malhotra,R.S. and Saxena,MC. 2001.Drought tolerance in chickpea and lentil in Mediterranean environments. Legume symposium proceedings p. 119-126, Rabat, Morocco

[28] Schneider , KA, M. Brothers and J.D.Kelly. 1997 a. Marker assisted selection to improve drought resistance in common bean .crop Sci.,37: 51-60.

[29] Silim, S.N.,Saxena,M.C. and Eriskin,W. 1993. Adaptation of lentil to the Mediterranean environment .II. response to moisture supply . Expt.Agric., 29:112118.

[30] Singh, B. N. and MacKill, D. J., in Proc. 2nd Int. Rice Genet. Symp. International Rice Research Institute, Los Banos, Philippines, 1991.

[31] Singh, BB and T. Matsui, 2002. Breeding cowpea varieties for drought tolerance.p.287-300.

[32] Turk, K.J. and A.E.Hall, 1980. Drought adaptation of cowpea II.Influence of drought onplant water statusand relations with seed yield.Agron.J.72:421427.
[33] Walker,D.W. and J.C.Miller. 1986Intraspecific variability for drought resistance in cowpea. ScientiaHorticulture, 29:87-100

[34] Walton, P. D., Can. J. Plant Sci., 1974, 54, 749-754.

[35] Watanabe, I.,S. Hakoyama,T. Terao and BBSingh.1997Evaluation methods for drought tolerance in cowpea.p.141-146.

[36] White,J.W. and S.P. Singh. 1991. Breeding for adaptation to drought .p.501-560

[37] Williams, T. V., Snell, R. S. and Cress, C. E., Crop Sci., 1969, 9, 19-23.

[38] Yadava, R.B.R and B.D. Patil. 1984. Screening of cowpea varieties for drought tolerance. Z. Pflanzenzuchtg,93:259-262. 